\title{
Comparison of variability in diameter and taper of gutta percha cones of different brands using Stereomicroscopy and Digital Micrometer
}

\author{
(c) N. Mishra', K. Magwa², M. Agarwal², MP Singh³, S. Singh², S. Thakur \\ 'Mansarovar Dental College Hospital and Research Center, Bhopal, India \\ ${ }^{2}$ People's College of Dental Sciences and Research Centre, Bhopal, India \\ ${ }^{3}$ Chirayu Medical College and Hospital, Bhopal, India \\ ${ }^{4}$ Sri Aurobindo College of Dentistry, Indore, Madhya Pradesh, India
}

\begin{abstract}
:
Aim: Variations in cone tip diameter while obturation can lead to premature binding, extrusion, or poor adaptability of GP to the canal walls and promotes microleakage and ultimately endodontic failure. The purpose of this investigation was to measure the variability from the listed cone tip diameter and taper of size \#25, 0.06 taper GP cones from three different brands with the help of stereomicroscope and digital micrometer.

Materials and methods: 45 GP points $(N=45)$ of Size \#25 with an 0.06 taper from three different brands were divided into three groups: Group A - Diadent Group B - K3 and Group C Pro- Taper Next. Each group have 15 GP $(n=15)$. The diameters (D0 and D3), tapers were measured according to the ANSI/ADA Specification No. 78 using stereomicroscope (accuracy of $0.001 \mathrm{~mm}$ ) and digital micrometer. Kruskall Wallis test was to detect any significant differences between two or more groups and Mann Whitney $U$ test for pairwise comparison. $p$ value $<0.05$ were considered as statistically significant.

Results: On comparing there was significant variability within the three brands using stereomicroscopy, the standard values for D0 diameter which was $0.25 \pm 0.23$, Protaper Next GP cones was the similar to the standardized values compared to Diadent and K3 GP cones which were significantly different from the standard values. On comparing diameter variation at D3, Protaper Next, $0.043 \pm 0.018$ was once again similar to its manufacturer standard values of $0.43 \pm 0.022$. Diadent showed mild variation with D3 Diameter of $0.44 \pm 0.017$ and $\mathrm{K} 3$ was significantly different from the standard values $\mathrm{K} 3$ was $0.41 \pm 0.018$.

Conclusions: The results of the current study indicate significant variability between GP cone brands for both diameter and taper. However, the high standard deviation values associated with most of the diameter and taper differences from manufacturer's nominal values also suggests high variability within individual brands.
\end{abstract}

Keywords: Obturation, Diameter variation, Endodontics, Gutta percha, Taper.

Received: 24.05.2021; accepted: 27.06.2021.

Conflict of interests: The authors declare no conflict of interests.

For citation: Niharika Mishra, Khushboo Magwa, Manish Agarwal, MP Singh, Santosh Kumar Singh, Sonal Singh Thakur. Comparison of variability in diameter and taper of gutta percha cones of different brands using Stereomicroscopy and Digital Micrometer. Endodontics today. 2021; 19(2):90-94. DOI: 10.36377/1683-2981-2021-19-2-90-94.

\section{INTRODUCTION}

The rationale behind the endodontic treatment is to extirpate the pulpal tissue, disinfecting, cleaning and shaping the root canal system (RCS) followed by obturation. The obturation entirely fills and seals the disinfected RCS with Gutta Percha (GP) in order to prevent bacterial microleakage from the oral environment, apical and periradicular tissues [1]. Fluid infiltration from the periradicular tissues seeps into the RCS via apical foramen and/or lateral canals providing nutrition to remaining bacteria and enables their proliferation [2]. An apical seal prevents the entry of tissue fluid into the canal, also preventing the exit of bacteria from the canal to the periradicular tissues $[3,4]$.

Gutta-percha (GP) has been used in dentistry for over 150 years and was introduced by Hill in 1847 which was then called as "Hills Stopping" [5]. This close adaptation of the GP to the prepared RCS paves way for a minimal amount of sealer and an efficient way to achieve a "snug" fit of the master cone before complete obturation. Despite its popularity as a root canal filling material, it lacks universal manufacturing standardization. The concept of standardizing instruments and dental obturating cones was first recommended by Ingle in 1955 [6,7]. The two current standards for dental GP obturating cones are the American National Standard Institute/American Dental Association (ANSI/ADA) Specification No. 78 published in 2000 and ISO 6877, published in 1995.

Although a perfect match between instrumented canal and GP cone is impossible, if the size and taper of the master cone differs significantly from the prepared area by the master file, insufficient obturation may result [8]. Variations in cone tip diameter can lead to premature binding, extrusion, or poor adaptability of GP to the canal walls and microleakage thus ultimately affecting the outcome of the treatment [9]. The purpose of this short study was to measure the variability from the listed cone tip diameter and taper of size \#25, 0.06 taper GP cones from three different brands with the help of stereomicroscope.

\section{MATERIALS \& METHODS}

Institutional ethical committee approval was obtained for the study (Ref/PCDS/ACAD/9/2015/24). The Total sample size was 45 GP points $(N=45)$ of Size \#25 with a 0.06 taper from three different brands: Diadent (Diadent Group International Inc., Vancouver, BC, Canada); K3 


\section{Исследования / Scientific researches}

[SybronEndo, Orange, CA], and Pro Taper Next [Dentsply/ Maillefer]. They were further divided into 3 group. Each group have 15 GP Points:

Group A $(n=15)$ had 15 GP points from Diadent while, Group B had 15 GP points $(n=15)$ from K3 and Group C with 15 GP points $(n=15)$ from Protaper Next.

The diameters and tapers were measured according to the protocol given by ANSI/ADA Specification No. 78 using a stereomicroscope (Leica MZ75, Wetzlar, Germany) (Figure 1) with an accuracy of $0.001 \mathrm{~mm}$. The cone diameter was measured at the projected tip diameter D0 and D3 (Figure $2 \& 3$ ) and digital micrometer [M \& W precision tool model No. IP65 set with $0.001 \mathrm{~mm}$ accuracy] (Figure 4). The Measurement was done by two blinded observers and the mean value was taken. The results were tabulated,

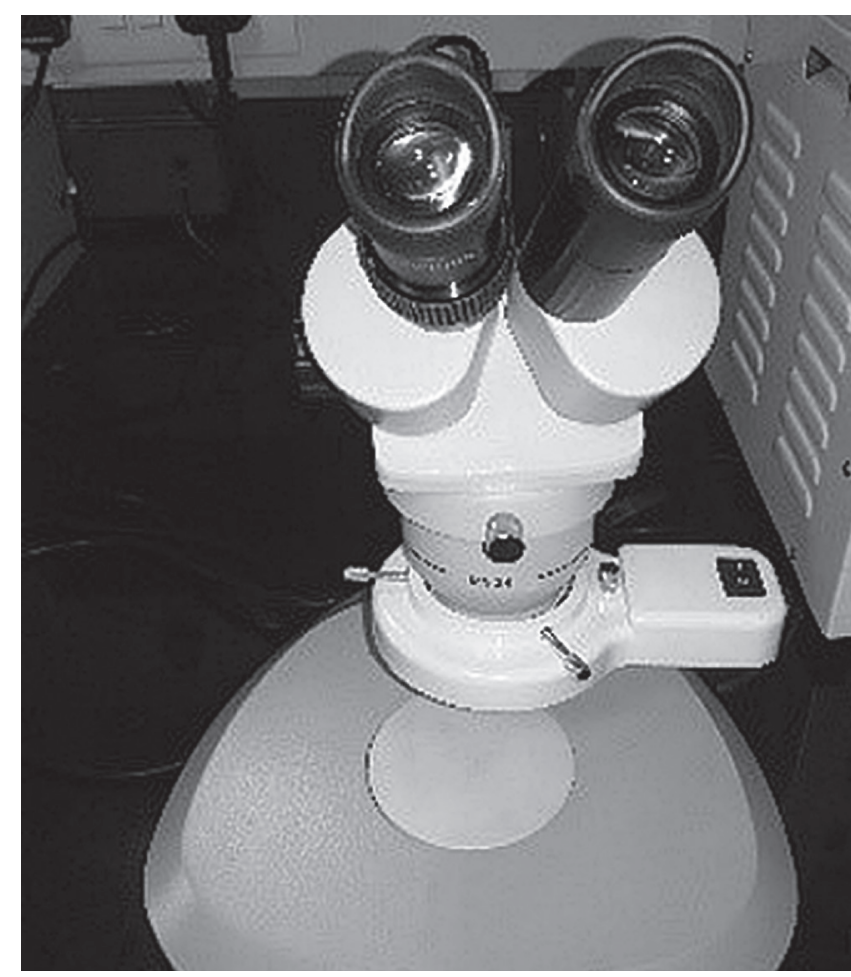

Fig. 1. The diameters and tapers were measured according to the protocol given by ANSI/ADA Specification No. 78 using a stereomicroscope (Leica MZ75, Wetzlar, Germany) with an accuracy of $0.001 \mathrm{~mm}$ presented as mean (range). Kruskall Wallis test was to detect any significant differences between two or more groups and Mann Whitney $U$ test for pairwise comparison. Statistical analysis was performed with Statistical Package for Social Services SPSS software version 23 (IBM SPSS Statistics for Windows, Version 23.0, Armonk, NY: IBM Corp. Released 2015). P values $<0.05$ were considered as statistically significant.

\section{RESULTS}

In our study, we analyzed the diameter and taper variations at D0 and D3 using stereomicroscopy and digital micrometer. Table 1 shows the comparison between the three brands with stereomicroscopy, the standard values for D0 diameter which was $0.25 \pm 0.23$, Protaper

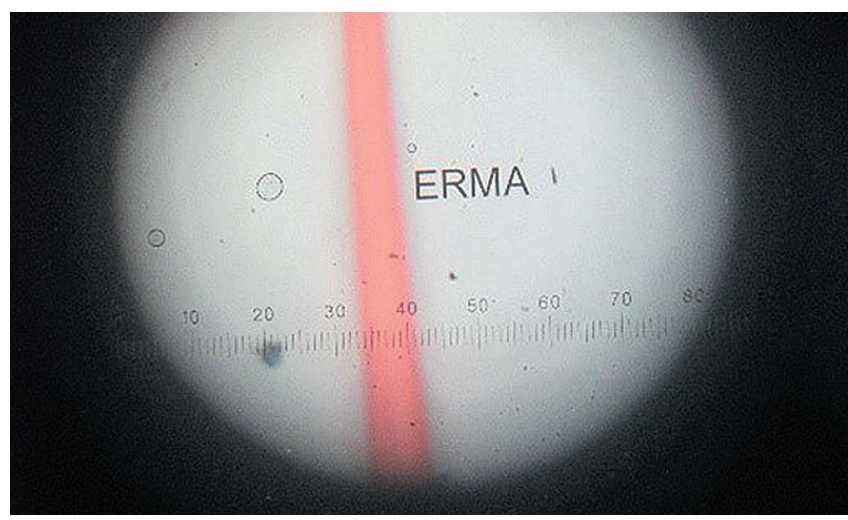

Fig. 2. Projected tip diameter DO

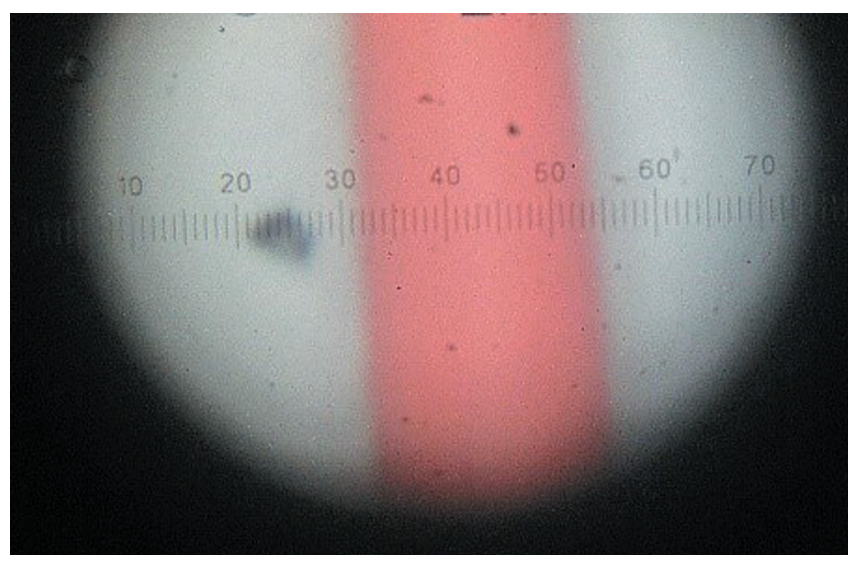

Fig. 3. Projected tip diameter D3

Table 1. Comparison of Diadent, Protaper Next and K3 D0, D3 and Taper values with standard values examined under Stereomicroscope.

\begin{tabular}{|c|c|c|c|c|c|}
\hline & \multirow{2}{*}{ Groups } & \multicolumn{2}{|c|}{ Mean \pm SD } & \multirow{2}{*}{$\begin{array}{c}\text { Unpaired } \\
\text { t-test }\end{array}$} & \multirow{2}{*}{$P$ value } \\
\hline & & Experimental Group value & Standard value & & \\
\hline \multirow{3}{*}{$\begin{array}{c}\text { DO } \\
(\mathrm{mm})\end{array}$} & & $0.27 \pm 0.021$ & $0.25 \pm 0.013$ & 3.136 & $0.004(<0.01)$, Sig. Diff \\
\hline & $\begin{array}{c}\text { Protaper } \\
\text { Next }\end{array}$ & $0.25 \pm 0.035$ & $0.25 \pm 0.013$ & 0.000 & $1.000(>0.05)$ Not Sig. \\
\hline & K3 & $0.28 \pm 0.017$ & $0.25 \pm 0.013$ & 5.429 & $0.000(<0.001)$, Sig. Diff \\
\hline \multirow{3}{*}{$\begin{array}{c}\text { D3 } \\
(\mathrm{mm})\end{array}$} & Diadent & $0.44 \pm 0.017$ & $0.43 \pm 0.022$ & 1.393 & $0.175(>0.05)$ Not Sig. \\
\hline & $\begin{array}{c}\text { Protaper } \\
\text { Next }\end{array}$ & $0.43 \pm 0.018$ & $0.43 \pm 0.022$ & 0.000 & $1.000(>0.05)$ Not Sig. \\
\hline & K3 & $0.41 \pm 0.018$ & $0.43 \pm 0.022$ & 2.725 & $0.01(<0.05)$, Sig. Diff \\
\hline \multirow{3}{*}{ Taper } & Diadent & $0.05 \pm 0.005$ & $0.06 \pm 0.003$ & 6.642 & $0.000(<0.001)$, Sig. Diff \\
\hline & $\begin{array}{c}\text { Protaper } \\
\text { Next }\end{array}$ & $0.05 \pm 0.006$ & $0.06 \pm 0.003$ & 5.774 & $0.000(<0.001)$, Sig. Diff \\
\hline & & $0.06 \pm 0.007$ & $0.06 \pm 0.003$ & 0.000 & $1.000(>0.05)$ Not Sig. \\
\hline
\end{tabular}




\section{2 Исследования / Scientific researches}

Next GP cones was the similar to the standardized values compared to Diadent and K3 GP cones and were significantly different from the standard values $(p<0.05)$. On comparing diameter variation at D3, the zone in the GP which is responsible for the apical seal. Protaper Next, $0.043 \pm 0.018$ was once again similar to its manufacturer standard values of $0.43 \pm 0.022$. For Taper, Significantly lower values of Diadent and Protaper Next from standard values was observed. For Taper, K3 values, $0.06 \pm 0.007$ was similar to standard value $0.06 \pm 0.003$ with no significant difference (Figure 5).

On observing with Digital micrometer, Diameter variation at D0 was significantly different for ProtaperNext and K3. Diadent had a diameter variation of $0.025 \pm 0.016$ was similar to standard value $0.25 \pm 0.013$. For D3, Significantly

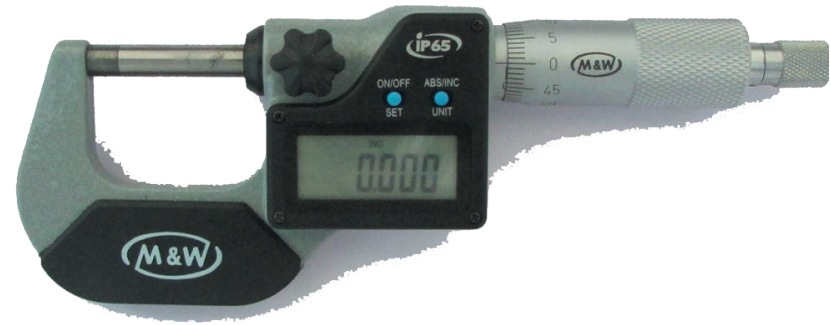

Fig. 4. Digital micrometer [M \& W precision tool model No. IP65 set with $0.001 \mathrm{~mm}$ accuracy] lower values of $\mathrm{K} 3$ from standard values. Table 2 shows the comparison between the mean values of three brands measured using digital micrometer.

Kruskal Wallis Test showed significant difference between the groups for Percentage deviation of D3 from standard values $(p<0.001)$. When compared pairwise, there was no significant difference between Diadent and ProtaperNext for Percentage deviation of D3 from standard values. But K3 showed significant Percentage deviation of D3 from standard values was significantly different

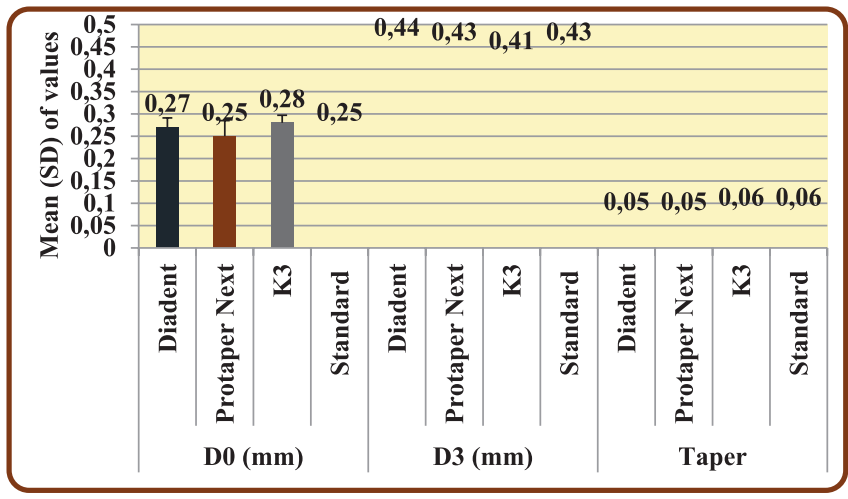

Fig. 5. Comparison of Diadent, Protaper Next and K3 D0, D3 and Taper values with standard values examined under Stereomicroscope.

Table 2. Comparison of Diadent, Protaper Next and K3 D0, D3 and Taper values with standard values examined under Digital micrometer.

\begin{tabular}{|c|c|c|c|c|c|}
\hline & \multirow{2}{*}{ Groups } & \multicolumn{2}{|c|}{ Mean \pm SD } & \multirow{2}{*}{$\begin{array}{c}\text { Unpaired } \\
\text { t-test }\end{array}$} & \multirow{2}{*}{ P value } \\
\hline & & Experimental Group value & Standard value & & \\
\hline \multirow{3}{*}{$\begin{array}{c}\text { D0 } \\
(\mathrm{mm})\end{array}$} & Diadent & $0.25 \pm 0.016$ & $0.25 \pm 0.013$ & 0.000 & $1.000(>0.05)$ Not Sig. \\
\hline & $\begin{array}{c}\text { Protaper } \\
\text { Next }\end{array}$ & $0.24 \pm 0.011$ & $0.25 \pm 0.013$ & 2.274 & $0.031(<0.05)$, Sig. Diff \\
\hline & K3 & $0.27 \pm 0.013$ & $0.25 \pm 0.013$ & 4.213 & $0.000(<0.001)$ Sig. Diff. \\
\hline \multirow{3}{*}{$\begin{array}{c}\text { D3 } \\
(\mathrm{mm})\end{array}$} & Diadent & $0.40 \pm 0.015$ & $0.43 \pm 0.022$ & 4.364 & $0.000(<0.001)$ Sig. Diff. \\
\hline & $\begin{array}{c}\text { Protaper } \\
\text { Next }\end{array}$ & $0.39 \pm 0.015$ & $0.43 \pm 0.022$ & 5.818 & $0.000(<0.001)$ Sig. Diff. \\
\hline & K3 & $0.41 \pm 0.016$ & $0.43 \pm 0.022$ & 2.848 & $0.008(<0.01)$ Sig. Diff. \\
\hline \multirow{3}{*}{ Taper } & Diadent & $0.06 \pm 0.005$ & $0.06 \pm 0.003$ & 0.000 & $1.000(>0.05)$ Not Sig. \\
\hline & $\begin{array}{c}\text { Protaper } \\
\text { Next }\end{array}$ & $0.06 \pm 0.004$ & $0.06 \pm 0.003$ & 0.000 & $1.000(>0.05)$ Not Sig. \\
\hline & K3 & $0.06 \pm 0.005$ & $0.06 \pm 0.003$ & 0.000 & $1.000(>0.05)$ Not Sig. \\
\hline
\end{tabular}

Table 3. Comparison of Stereomicroscope and Digital Micrometer D0, D3 and Taper values in Diadent, Protaper Next and K3 groups.

\begin{tabular}{|c|c|c|c|c|c|}
\hline & \multirow{2}{*}{ Groups } & \multicolumn{2}{|c|}{ Measurements (Mean \pm SD) } & \multirow{2}{*}{$\begin{array}{c}\text { Unpaired } \\
\text { t-test }\end{array}$} & \multirow{2}{*}{ P value } \\
\hline & & Experimental Group value & Standard value & & \\
\hline \multirow{3}{*}{$\begin{array}{c}\text { DO } \\
(\mathrm{mm})\end{array}$} & Diadent & $0.27 \pm 0.021$ & $0.25 \pm 0.016$ & 2.600 & $0.015(<0.05)$, Sig. Diff \\
\hline & $\begin{array}{c}\text { Protaper } \\
\text { Next }\end{array}$ & $0.25 \pm 0.035$ & $0.24 \pm 0.011$ & 1.125 & $0.277(>0.05)$ Not Sig. \\
\hline & K3 & $0.28 \pm 0.017$ & $0.27 \pm 0.013$ & 1.081 & $0.289(>0.05)$ Not Sig. \\
\hline \multirow{3}{*}{$\begin{array}{l}\text {-D3 } \\
\text { (mm) }\end{array}$} & Diadent & $0.44 \pm 0.017$ & $0.40 \pm 0.015$ & 6.831 & $0.000(<0.001)$, Sig. Diff. \\
\hline & $\begin{array}{c}\text { Protaper } \\
\text { Next }\end{array}$ & $0.43 \pm 0.018$ & $0.39 \pm 0.015$ & 5.642 & $0.000(<0.001)$, Sig. Diff. \\
\hline & K3 & $0.41 \pm 0.018$ & $0.41 \pm 0.016$ & 0.106 & 0.916 (>0.05) Not Sig. \\
\hline \multirow{3}{*}{ Taper } & Diadent & $0.05 \pm 0.005$ & $0.06 \pm 0.005$ & 0.354 & $0.726(>0.05)$ Not Sig. \\
\hline & $\begin{array}{c}\text { Protaper } \\
\text { Next }\end{array}$ & $0.05 \pm 0.006$ & $0.06 \pm 0.004$ & 3.334 & $0.002(<0.01)$, Sig. Diff \\
\hline & K3 & $0.06 \pm 0.007$ & $0.06 \pm 0.005$ & 0.595 & $0.556(>0.05)$ Not Sig. \\
\hline
\end{tabular}




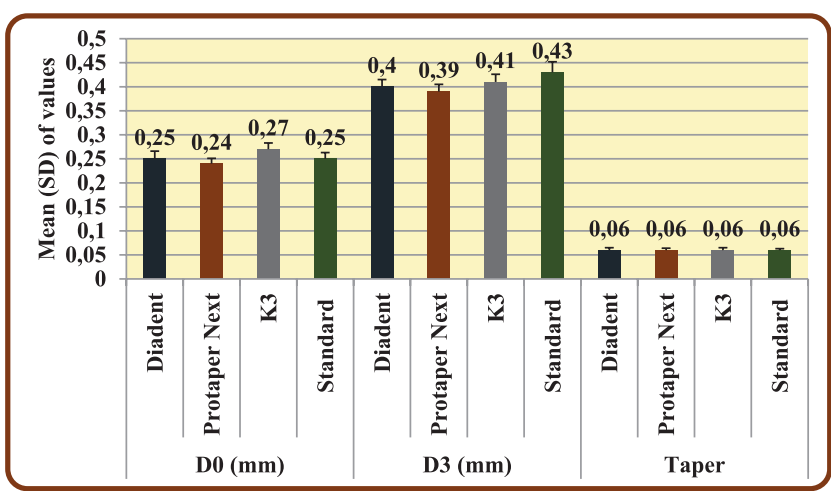

Fig. 6. Comparison of Diadent, Protaper Next and K3 D0, D3 and Taper values with standard values examined under Digital micrometer.

from Diadent and Protaper Next (Figure 6). For Taper, K3, Diadent and Protaper values are similar to standard values. Stereomicroscope was accurate in determining the diamtete and taper variation compared to the digital micrometre [Table 3 \& Figure 7].

\section{DISCUSSION}

Clinically, while selecting GP cones for obturation, unexpected variations in cone tip diameter leads to incomplete obturation, lack of tridimensional seal and subsequently endodontic failure. This study was the first of its kind to observe and compare the diameter variability and taper dimension of GP cones from three different brands using stereomicroscopy and digital micrometre. We also compared which of the novel devices i.e., stereromicroscope and digital micrometre was accurate in determining the taper and diameter variation of GP cones from the standard values.

According to the current standards, the accepted diameter of GP cone may vary from 0.005 to $0.007 \mathrm{~mm}$, as followed by most of reputed companies. Such variation means that cone of one stated size can be one size above and/or below, for example, ISO \# 25 cone can have ISO \# 30 or ISO \# 20. About $60 \%$ of root canal failures occur due to incomplete obturations. This requires that GP cones used for obturation be standardized and also closely match with the working length of the last instrument.

In 2006, Cunningham et al.[3] evaluated size 30/.04 gutta-percha points of five different commercial brands: Diadent ${ }^{\circledR}$, Lexicon ${ }^{\circledR}$, Maillefer ${ }^{\circledR}, \mathrm{K} 3{ }^{\circledR}$ and Maxima ${ }^{\circledR}$. The measurement of the D0 diameter through a measuring microscope with precision of $0.001 \mathrm{~mm}$. Since the ANSI/ADA Specification no. 78 established a variation of $\pm 0.07 \mathrm{~mm}$ for D0 in size \#30 points, the acceptable pattern for the points measured at D0 would be of 0.23 $0.37 \mathrm{~mm}$. The taper of the points was determined from D3 and D16 diameter. The authors observed a significant variability of the diameter and taper for GP points observed; but, all results were within the limit accepted by the ANSI/ADA Specification no. 78, because they did not surpass $\pm 0.07 \mathrm{~mm}$. In our study, confirms findings of the study where the diameter variability at D0, ProtaperNext GP points were closer to the standard values. However, K3 and diadent were within standard limits. Kunert et al analyzed through two-gauge rulers of different brands, the adaptation at D0 of sizes F1, F2 and F3 gutta-percha points of ProTaper ${ }^{\circledR}$ system in relation to the $\mathrm{NiTi}$ instruments of the same system. The authors found that none of the measuring rulers used exhibited ideal conditions

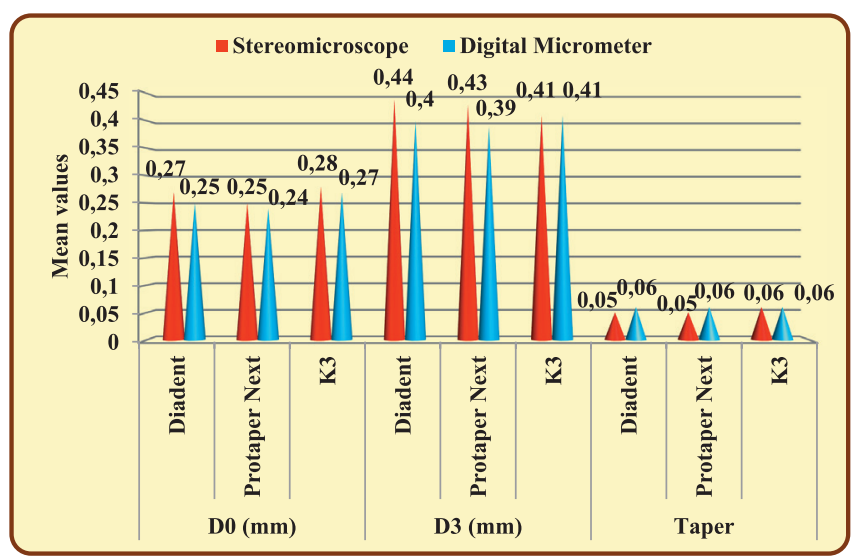

Fig. 7. Comparison of Stereomicroscope and Digital Micrometer D0, D3 and Taper values in Diadent, Protaper Next and K3 groups.

for the assessment of the adaptation of the GP points and rotary instruments of the ProTaper ${ }^{\circledR}$ system. Additionally, it was also seen that the diameter variation of GP points at D0 varied [10].

The diameter between D0 and D3, the zone responsible for the apical seal showed variation between the two brands but were within the range of standard values, ProtaperNext GP points was similar to the standard values on observation through stereomicroscope. K3 and diadent were not exactly similar to the standard values but they were within the permissible range. It is necessary that the gutta-percha point used as master cone have D0 diameter as closer as possible to the position corresponding to the instrument used to construction the apical stop [11]. This correspondence between the diameter of the GP points and the instruments will promote a proper locking of the master cone at D0 and D3, because it is at this diameter that the apical stop is constructed. From our findings, there was no significant difference between the three brands on assessing the D0 Diameter variability between the three brands.

Despite carefully following the standard manufacturing procedures and packing, mechanical deformation can also occur. This variability of GP cones such as shrinkage and expansion might be caused due to it's high plasticity during transportation, storage but to there seems to be a lack of information regarding the influence of environmental changes on the. GP cones $[12,14,15]$. There are also concerns about fit of GP along the entire length of root canal from apical to coronal third as any discrepancy can lead to leakage. This can result in either over or under obturations and endodontic treatment failure. In these situations, clinician resorts to cut the tip of GP cones by using GP gauge or use a smaller size GP cones arbitrarily. Due to flexible nature of GP cones and chances of dimensional change with change in temperature, there might be variation in diameter measurement. Further, measuring diameter of these types of materials with metal digital caliper is extremely difficult as slight change in pressure can alter the size, which could explain why measurements made by digital micrometre in our study did not yield accurate values.

The results of our study indicate a significant variability between GP cone brands for both diameter and taper. The actual diameter values across brands varied from 0.2495 to $0.251 \mathrm{~mm}$, while the taper measurements across brands ranged from 0.0595 to $0.0605 \mathrm{~mm}$. These results 
substantiate the clinical observation that there is great GP cone variability between and within GP brands for both diameter and taper.

In this study, the brand that presented the best result was ProtaperNext. Comparing Stereomicroscopy and digital micrometre, the former proved to be accurate in its measurement of the GP points. This could be attributed to the standardized procedures in examining the GP point compared to digital micrometer where it is hand held perpendicularly and measured thereby subjecting to manual errors. It should be expected that there will be variability within and between different manufacturers. Besides the lack of narrow specification tolerance values, the diameter.

\section{REFERENCES:}

1. Godiny M, Hatam R, Khavid A, Khanlari S. Apical Microleakage in Root Canals Containing Broken Rotary Instruments. Iran Endod J. 2017;12(3):360-5.

2. Narayanan LL, Vaishnavi C,Endodontic Microbiology, J Conserv Dent. 2010 Oct-Dec; 13(4): 233-239

3. Carvalho E, Junior JA, Malvar MF, Albergaria S. Avaliação do selamento apical em dentes obturados pela técnica da condensação lateral híbrida, de Tagger e Thermafil. Revista de Ciências Médicas e Biológicas, Salvador, 2006; 5(1): 239-244.

4. Mozayeni MA, Dianat O, Tahvildari S, Mozayani M, Paymanpour P. Subcutaneous Reaction of Rat Tissues to Nanosilver Coated GuttaPercha. Iran Endod J. 2017;12(2):157-61.

5. Taft J. A practical treatise on operative dentistry. Philadelphia: Lindsay and Blakiston,1859;75-93

6 . Ingle J. The need for endodontic instrument standardization. Oral Surg Oral Med Oral Pathol 1955;8:1211-3.

7. Ingle J, LeVine $M$. The need for uniformity of endodontic instruments, equipment and filling materials. In: Grossman L, ed. Transactions of the second international conference on endodontics. Philadelphia: University of Pennsylvania Press,1958;234:123-42.

8. Schulte A, Pieper K, Charalabidou O, Stoll R, Stachniss V. Prevalence and quality of root canal fillings in a German adult population. A survey of orthopantomograms taken in 1983 and 1992. Clin Oral Investig. 1998;2(2):67-72.
The clinician should keep in mind the variability and in certain situation, it is best to use a smaller size tip diameter.

\section{CONCLUSIONS}

To be efficient and productive, the clinician must depend on the manufacturer's reported diameter and taper of GP cones to be as accurate as possible. The clinician should anticipate variability from the manufacturer's stated GP cone diameter and taper. Further research needs to be conducted in this area. On comparing between the three groups, the periapical diameter of ProTaper Next was similar to the manufacturing standard values without any major deviation compared to the other brands while K3 brand of GP cone showed a taper variability similar to that of the standard value.

9. Cunningham KP, Walker MP, Kulild JC, Lask JT. Variability of the diameter and taper of size \#30, 0.04 gutta-percha cones. J Endod. 2006;32(11):1081-1084.

10. Kunert GK, Melo TA, Oliveira EP, Barletta FB. Accuracy of the tip diameter on gutta-percha cones of different tapers. Rev Assoc Cir Dent. 2008;62:309-13.

11. Waechter F, Antunes RO, Irala LED, Limongi O. Avaliação comparativa entre o diâmetro de cones estandardizados e cones secundários B8 calibrados por régua calibradora, distando $1 \mathrm{~mm}$ das suas pontas (D1). RSBO. 2009;6(1):34-43.

12. Wei YJ, Silikas N, Zhang ZT, Watts DC. Hygroscopic dimensional changes of self-adhering and new resin-matrix composites during water sorption/desorption cycles. Dent Mater. 2011;27(3):259-66.

13. Zaslansky P, Fratzl P, Rack A, Wu MK, Wesselink PR, Shemesh H. Identification of root filling interfaces by microscopy and Tomography methods. Int Endod J. 2011;44(5):395-401.

14. Johansson BI. A methodological study of the mechanical Properties of endodontic gutta-percha points. J Endod. 1980;6(10):7813.

15. Moon HJ, Lee JH, Ahn JH, Song HJ, Park YJ. TemperatureDependent rheological property changes of thermoplastic gutta percha root filling materials. Int Endod J. 2015;48(6):556-63.

\section{AUTHOR INFORMATION:}

N. Mishra ${ }^{1}$ - MDS, Assistant professor, ORCID ID:0000-0002-1065-4871.

Kh. Magwa ${ }^{2}-$ MDS

M. Agarwal ${ }^{2}-\mathrm{MDS}, \mathrm{HOD}$

MP. Sing $h^{3}-$ MDS, Professor \& HOD

S. Sing ${ }^{2}-$ MDS, Professor.

S. Thakur - MDS, Senior Lecturer.

'Department of Conservative Dentistry \& Endodontics, Mansarovar Dental College Hospital and Research Center, Bhopal.

${ }^{2}$ Department of Conservative Dentistry \& Endodontics, People's College of Dental Sciences and Research Centre, Bhopal

${ }^{3}$ Dentistry Department, Chirayu Medical College and Hospital, Bhopal

${ }^{4}$ Department of Conservative Dentistry \& Endodontics, Sri Aurobindo College of Dentistry, Indore, Madhya Pradesh

Coordinates for communication with authors: Niharika Mishra, E-mail: dentistniharika@gmail.com 